\section{THE COLLEGE'S MEDALS AND PRIZES}

The Court of Electors has recently reviewed College prizes, and have instituted a new Research Prize to supersede the Bronze Medal and Prize and the Divisional Prizes.

\section{GASKELL MEDAL AND PRIZE}

In addition to the Medal the award attached to this prize is $£ 150$. The annual examination for the prize will be held in April or May, 1979. Entries should be sent in by 31 March 1979.

The Prize has always been considered one of the foremost academic distinctions obtainable in clinical psychiatry, and members are asked to bring it to the notice of suitable candidates at their hospitals who may be eligible to compete.

Full particulars of the Regulations are given below, and entry forms may be obtained on application to the Dean.

\section{Regulations}

The examination must be held in England according to the terms of the Trust.

Candidates must produce evidence of (a) having been qualified medical officers in one or more psychiatric hospitals or clinics in psychiatry in the United Kingdom or elsewhere in the Commonwealth or in the Republic of Ireland for at least two years; (b) having passed the M.R.C.Psych. examination or possessing any other degree or diploma in psychological medicine.

Candidates must be over 23 and under 35 years of age on 1 January of the year of the examination.

The examination includes a written paper, a clinical and an oral.

An entry fee of $£ 5$ is charged, returnable to bona fide candidates.

\section{RESEARCH PRIZE}

A College Prize will be awarded for Research.

The value of the prize will be $£ 150$.

A limit of two such prizes will be awarded each year.

No prize will be awarded if a sufficient standard is not reached.

The Examiners for the Research Prize will be nominated jointly by the Court of Electors and Research Committee.

Entrance for the Prize will be limited to Members (or Inceptors) of the College below the rank of Consultant Psychiatrist (or equivalent).

Reports of research carried out by candidates for the Prize should be submitted to the Dean by 31 March of each year. Reports received after this date will be accepted as entries for the Prize for the following year.

\section{M.R.C.PSYCH. EXAMINATIONS—SPRING 1979}

The next M.R.C.Psych. Examinations will take place on the following dates:-

Preliminary Test -Wednesday, 28 March 1979

Membership Examination -Wednesday, 9 May 1979 (written papers)

Membership Examination - Monday, 14 to (clinicals and orals) Wednesday, 17 May 1979

The closing date for receipt of entries is WEDNESDAY, 28 FEBRUARY 1979.

The fees for each entry are $\mathbf{1 3 0}$ for the Preliminary Test and $£ 50$ for the Membership Examination.

The written papers will be held in London, Birmingham, Glasgow and Dublin. The clinical and oral examinations will be held in London, Birmingham and Glasgow.

Prospective candidates are reminded that late entries WILL NOT BE ACCEPTED. Where candidates have undertaken part-time or overseas experience in psychiatry, or are required to submit the name and address of their Clinical Tutor or Consultant Chief, the entry forms should be submitted at least three weeks in advance so that the application may be finalised before the closing date is reached. All candidates are required to pass the Preliminary Test before sitting for the Membership Examination.

Regulations and application forms are obtainable from the Examinations Secretary, 17 Belgrave Square, London SWIX 8PG, together with copies of past Essay Question Papers at 50p per set for 1971-1975, 20p per set for 1976 and 25p per set for 1977-1978, inclusive of UK postage. These sets include sample multiple choice questions. Airmail postage is extra according to area.

The 4th Edition of the 'Reading List in Psychiatry' is available direct from the printers, Messrs. Headley Brothers Ltd., Ashford, Kent TN24 $8 \mathrm{HH}$, at a cost of 40p including UK postage. Airmail postage extra according to area. Cheques/postal orders should be made payable to 'Headley Brothers Ltd.'

All Members and Fellows are asked to bring this announcement to the notice of any prospective candidates who may be working under their guidance.

Thomas BeWLEY

Dean

\section{MIDLAND DIVISION}

The afternoon session at the Spring Meeting on $\mathbf{3 0}$ March will be devoted to contributions by members of the Division. Those interested in presenting short papers on clinical or research topics are invited to submit their papers or abstracts to Dr. R. Palmer, Clinical Sciences Building, Leicester Royal Infirmary, Leicester. 